\title{
Effect of Material Location and Tool Rotational Speed on the Mechanical Properties of Dissimilar Friction Stir Welded Aluminum Alloys (5083-H321to 6061-T6)
}

\author{
D. Devaiah, Dr.K. Kishore and Dr.P. Laxminarayana
}

\begin{abstract}
The use of fusion welding process for 5083-H321 and 6061-T6 alloys is not preferred because of the heat generated from the thermal cycle of the welding which can affect the heat treatments of base metals. In this way, solid state nature of friction stir welding (FSW) process is by and large utilized as a part of request to join these dissimilar alloys. Friction stir welding (FSW) is carried out at different rotational speeds of $560 \mathrm{rpm}, 900 \mathrm{rpm}$, and $1800 \mathrm{rpm}$ with H13 tool steel at a constant welding speed of $40 \mathrm{~mm} / \mathrm{min}$, tilt angle of 20 and axial force of $5 \mathrm{KN}$. This experimental study presents the effect of variable rotational speeds on microstructure, hardness, Impact energy, and tensile properties of 5083-H321 and 6061-T6 alloys joints produced by FSW. Experimental results have shown that defect free friction stir welded joints of good quality successfully produced from $5 \mathrm{~mm}$ thick sections of these alloys. It is observed that the joint fabricated using $\mathrm{H} 13$ tool material at a rotational speed of $900 \mathrm{rpm}$ obtained higher mechanical properties as compared to those of $560 \mathrm{rpm}$, and $1800 \mathrm{rpm}$ when AA5083 located at advancing side.
\end{abstract}

Keywords--- Friction Stir Welding, Dissimilar Alloy, Mechanical Properties, Rotational Speeds, H13 Tool Steel, Welding Speed, Advance Side.

\section{INTRODUCTION}

$\mathrm{F}$ RICTION stir welding (FSW) is a solid-state joining process that has been invented at The Weld Institute (TWI, United Kingdom), and patented in 1991 by Wayne Thomas under research funded by in part by the National Aeronautics and Space Administration (NASA) [1] . It is an adaptation of the friction welding process. FSW is a endless process that involves plunging a portion of a specially shaped rotating tool between the butting faces of the joint [2]. The joint line, forcing the plasticized material to coalesce. The shoulder prevents the plasticized material from being expelled out of the weld. The tool is moved relatively along relative

D. Devaiah, PhD Scholar, Department of Mechanical Engineering, OU, Hyderabad, India.E-mail:deva7167@gmail.com

Dr.K. Kishore, Professor, Department of Mechanical Engineering, Vasavi College of Engineering, Hyderabad, India. E-mail: kkishore65@rediffmail.com

Dr.P. Laxminarayana, Professor, Department of Mechanical Engineering, University College of Engineering, Hyderabad, India. E-mail: plax@osmania.ac.in

DOI:10.9756/BIJIEMS.8311 motion between the tool and the substrate generates frictional heat that creates a plasticized region around the immersed portion of the tool [3-5]. The shoulder prevents the plasticized material from being expelled out of the weld. The tool moved generally along the joint line, compelling plasticized material to mix behind the tool to frame solid-phase joint [6]. From its creation, the procedure received overall consideration, specialized organizations from Japan, Europe and USA are utilizing the technology for production [7]. It can be utilized additionally to welding $\mathrm{Al}$ alloys of various alloy groups or dissimilar materials, composites with metal matrix and plastics [8].Other materials for example copper, magnesium, titanium zinc and even steel can be welded with this procedure. The procedure introduces several advantages when compared with common arc welding processes, for the most part in the welding of $\mathrm{Al}$ alloys. Challenges identified with affectability of solidification cracking, gas porosity due to the hydrogen absorbed during welding and thermal distortion, routine in fusion welding process; will not occur in FSW [9]. Different advantages of this procedure are good strength and ductility along with reduction of distortion and residual stress, consumables are not required, improved safety standards because of the nonappearance of toxic gases and spatter, the process can work in all positions (horizontal, vertical, and so on), effortlessly automated on simple vertical milling machines with bring down setup costs and less training [10]. Friction Stir Welding finds applications in diverse areas. Potential applications are space shuttle fuel tanks, aluminum decking for car ferries, ship buildings and automotive structural components. The continually developing list of FSW clients incorporates Airbus, Eclipse, NASA, Boeing, US Navy, Mitsubishi and Kawasaki [11]. FSW process can be effectively applied to a variety of joints designs like lap joints, $\mathrm{T}$ butt joints, butt joints and even fillet joints [3]. In a FSW process, advancing side (AS) is the side where the direction of the tool rotation and traverse movement direction are the same and the side where the velocity vectors (of tool rotation and traverse movement) are opposite is referred to as retreating side (RS) [12]. Heat treatable aluminum alloys (6061) and non heat treatable aluminum alloys (5083) are specially produced for important applications with advanced mechanical properties of good strength and ductility but unfortunately sometimes with the disadvantage of unsuitability to conventional welding processes. Therefore in basic utilizations of aviation and similar, where special heat treatable alloys are used only FSW be applied. 
Although friction stir welding of the same (or similar) aluminum alloys have been studied largely in literature [12-14]not much study have been found regarding FSW of dissimilar aluminum alloys [15-18], in particular of 5083-H321 to 6061-T6 alloys. In this paper, friction stir weldability and mechanical properties of the joint generated by FSW of dissimilar aluminum alloys (5083-H321 alloy to 6061-T6) are studied and trial results are given as new outcomes.

\section{EXPERIMENTAL}

The AA5083 and AA6061 alloy plates of $5 \mathrm{~mm}$ thickness were cut into the required size $(200 \mathrm{~mm} \times 75 \mathrm{~mm})$ by power hacksaw cutting and milling. The joint was obtained by butt joining the two plates and stirring them together with a rotating tool on the vertical milling machine. Schematic sketch of the tool and weld joint is as displayed in Fig.1 and Fig.2 Non-consumable H13 tool Steel with concave shoulder and scrolling is chosen as tool material to create the joints, because of its high strength at elevated temperature, thermal fatigue resistance and low wear resistance. The diameter of the shoulder and pin utilized were $18 \mathrm{~mm}, 6 \mathrm{~mm}$ respectively and length of the pin is $4.7 \mathrm{~mm}$. The butted plates were clamped on a steel backing plate. The macrographs of VMM displayed in Fig.3. For different testing the required dimensions of the samples were cut from the region under the tool shoulder (i.e. stir zone) by utilizing wire EDM. The welding tool is tilted by an angle of 2 degree with reference to the welded plates and tool was made to rotate in the clockwise direction. A constant axial force is applied for all the joints. The FSW joints were fabricated with taper threaded tool pin profile and observed to be defect free welds. Specimens for tensile testing were taken in transverse to the weld direction and machined as per ASTM E8-M4 standards. Tensile test was conducted using computer controlled universal testing machine with a cross head speed of $0.5 \mathrm{~mm} / \mathrm{min}$. Specimens for impact testing were prepared along the transverse direction of the weld and machined according to ASTM A370 norms. The charpy "V" notch impact test was conducted at ambient temperature utilizing pendulum type impact testing machine. The amount of energy absorbed in fracture was recorded and the absorbed energy is characterized as the impact toughness of the material. The Schematic diagram of tensile test specimen and the schematic diagram of charpy impact test specimen were indicated in Fig.4. and Fig.5. separately. Specimens were prepared by cutting at the center of the joint along the transverse direction for microhardness analysis. Microhardness test was completed utilizing Vickers digital micro hardness tester with a $0.5 \mathrm{~kg}$ load for $10 \mathrm{~s}$ duration. The microhardness was measured at an interval of $3 \mathrm{~mm}$ across the WZ, Thermo-Mechanical Affected Zone (TMAZ), and Heat-Affected Zone (HAZ) and (base metal) BM. Defect free welds were gotten at all the conditions such as tool rotation speed at 560rpm, 900rpm, $1800 \mathrm{rpm}$ and weld speed at $40 \mathrm{~mm} / \mathrm{min}$. The microstructure at the weld zone of friction stir welded joint at the state of weld speed at $40 \mathrm{~mm} / \mathrm{min}$ was found to have a finer grains when compared to other weld conditions as a result of dynamic recrystallization. The joints made with tool rotation speed at $900 \mathrm{rpm}$ and weld speed at $40 \mathrm{~mm} / \mathrm{min}$ when AA5083 located at advancing side brought about great mechanical properties as compared with other weld conditions due to adequate heat generation and proper mixing of the material in the weld zone.

Table 1: Chemical Composition of Parent Materials (Mass Fraction, \%)

\begin{tabular}{llllllll}
\hline Alloy & $\mathrm{Mg}$ & $\mathrm{Mn}$ & $\mathrm{Cu}$ & $\mathrm{Cr}$ & $\mathrm{Si}$ & $\mathrm{Fe}$ & $\mathrm{Al}$ \\
\hline AA6061-T6 & 1.046 & 0.101 & 0.259 & 0.195 & 0.533 & 0.262 & Bal \\
AA5083-H321 & 4.0 & 0.548 & 0.065 & 0.10 & 0.145 & 0.238 & Bal \\
\hline
\end{tabular}

Table 2: Mechanical Properties of Parent Materials

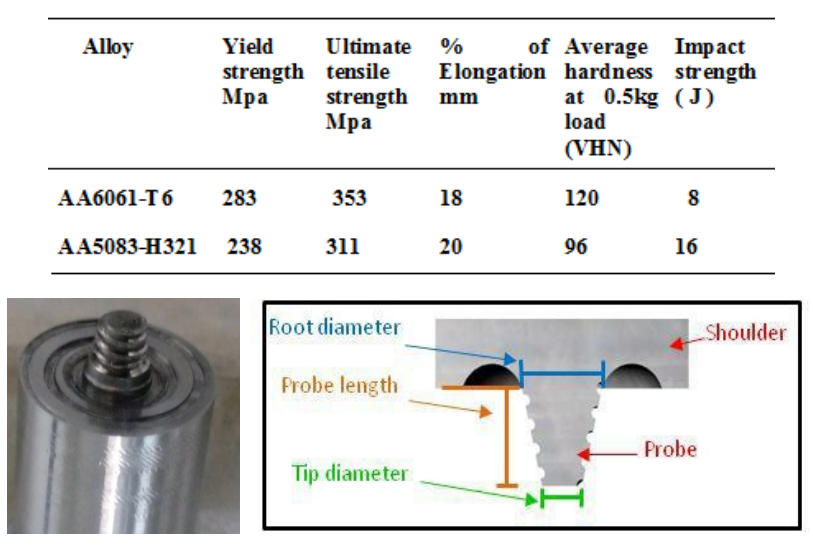

(a)

(b)

Figure 1: (a) Weld Tool (b) Probe Dimensions

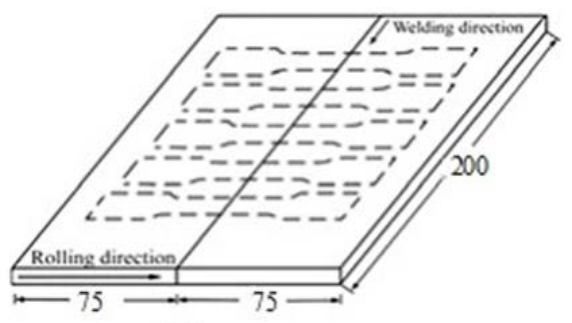

(a)

Figure 2: The Schematic Diagram of AA5083 to A6061Alloy Plates Used for FSW

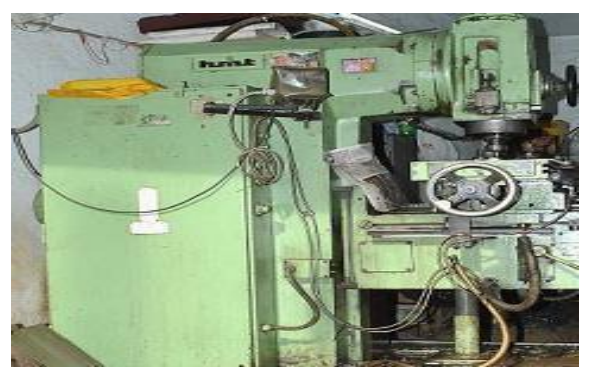

Figure 3: The Macrographs of Vertical Milling Machine

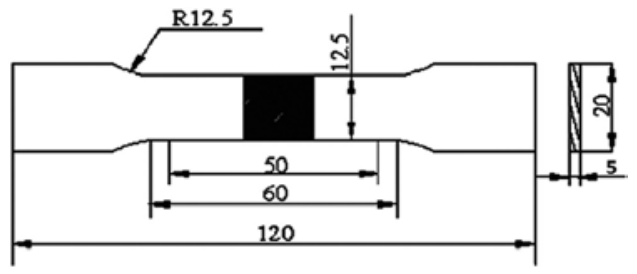

Figure 4: The Schematic Diagram of the Tensile Specimen 


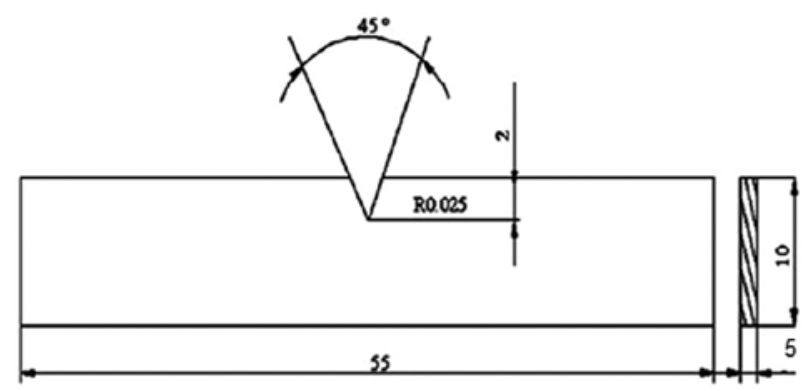

Figure 5: The Schematic Sketch of Charpy Specimen

Table 3: Process Parameters Used to Fabricate the Joints

\begin{tabular}{|c|c|c|c|}
\hline Exp No & $\begin{array}{l}\text { Weld Speed } \\
\mathrm{mm} / \mathrm{min}\end{array}$ & $\begin{array}{l}\text { Rotational Speed } \\
\text { rpm }\end{array}$ & Direction of Weld \\
\hline 561 & \multirow[t]{3}{*}{40} & 560 & \multirow{3}{*}{$\begin{array}{l}\text { AA5083 Advances side \& } \\
\text { AA6061 Retreat side }\end{array}$} \\
\hline 562 & & 900 & \\
\hline 563 & & 1800 & \\
\hline 651 & \multirow[t]{3}{*}{40} & 560 & \multirow{3}{*}{$\begin{array}{l}\text { AA6061 Advances side \& } \\
\text { AA5083 Retreat side }\end{array}$} \\
\hline 652 & & 900 & \\
\hline 653 & & 1800 & \\
\hline
\end{tabular}

\section{RESUlTS AND DisCUSSIONS}

\section{A. Tensile Properties}

The effect of tool rotational speed (i.e. H13 tool steel material) on Mechanical properties such as tensile strength, yield strength and \% of elongation of dissimilar Friction Stir Welded AA5083 and AA6061 alloy joints are presented in Table 3. In FSW, tool rotation speed brings about stirring and mixing of material around the rotating pin which thus increment the temperature of the metal. It gives off an impression of being the most noteworthy process variable since it is tends to impact the transitional velocity. It was realized for some times that the highest temperature was observed to be a strong function of tool rotation speed [3]. At higher rotational speed (1800rpm), results in increase of ultimate tensile strength, yield strength and \% of elongation of FSW joints is low. At the point when the rotational speed was increased from 560rpm, correspondingly the ultimate tensile strength additionally increments and achieves a maximum at $900 \mathrm{rpm}$. In the event that the rotational speed is above 900 rpm, the tensile strength of the joint reduced. Higher tool rotational speed (1800 rpm) typically bringing about higher heat input per unit length and slower cooling rate in the FSW zone causes excessive grain improvement, which in this way provoke to cut down tensile strength of the joints. A higher rotational speed also causes expensive release of stored materials to the upper surface, which produces small scale voids in the stir zone and this might be one reason for lower tensile properties of the joints, even at lower rotational speed (560 rpm) brings about lower tensile properties which are because of absence of stirring and lower heat input per unit length that leads to lacking plasticization. It is observed that the joint fabricated at a tool rotational speed of $900 \mathrm{rpm}$ made of exhibited higher tensile strength, yield strength and \% of elongation and this might be because of optimum heat generation which is adequate to bring about free flow of plasticized material and sufficient mechanical working.
Table 4: Effect of Rotational Speed on Mechanical Properties of AA5083 toAA6061 Alloy

\begin{tabular}{ccccccc}
\hline \multirow{2}{*}{ EXP NO } & $\begin{array}{c}\text { UTS } \\
(\mathrm{MPa})\end{array}$ & $\begin{array}{c}\text { YS } \\
(\mathrm{MPa})\end{array}$ & $\begin{array}{c}\% \mathrm{EL} \\
(\mathrm{mm})\end{array}$ & $\begin{array}{c}\mathrm{MH} \\
(\mathrm{VH})\end{array}$ & $\begin{array}{c}\text { IE } \\
(\mathrm{J})\end{array}$ & $\begin{array}{c}\text { Joint } \\
\text { efficiency }\end{array}$ \\
\hline 651 & 171 & 142 & 3.03 & 70 & 20 & 54.9 \\
652 & 178 & 147 & 5.2 & 74 & 26 & 57.2 \\
653 & 169 & 110 & 4.7 & 66 & 24 & 54.3 \\
561 & 179 & 149 & 5 & 78 & 25 & 57.6 \\
562 & 196 & 154 & 5.8 & 84 & 29 & 63 \\
563 & 175 & 121 & 5.4 & 75 & 26 & 56.3 \\
A.A 5083 & 311 & 238 & 20 & 96 & 16 & \\
A.A 6061 & 353 & 283 & 18 & 120 & 8 & \\
\hline
\end{tabular}

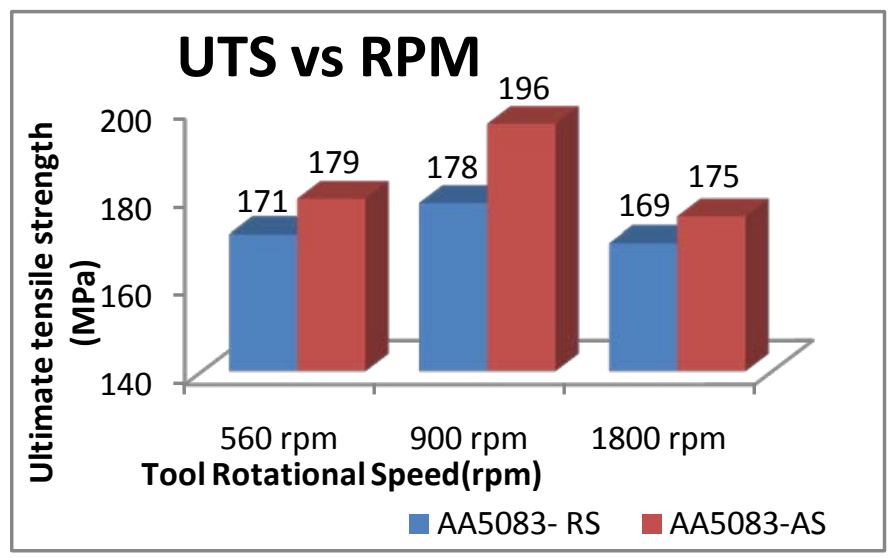

Figure 6: Effect of Tool Rotational Speed on Tensile Strength

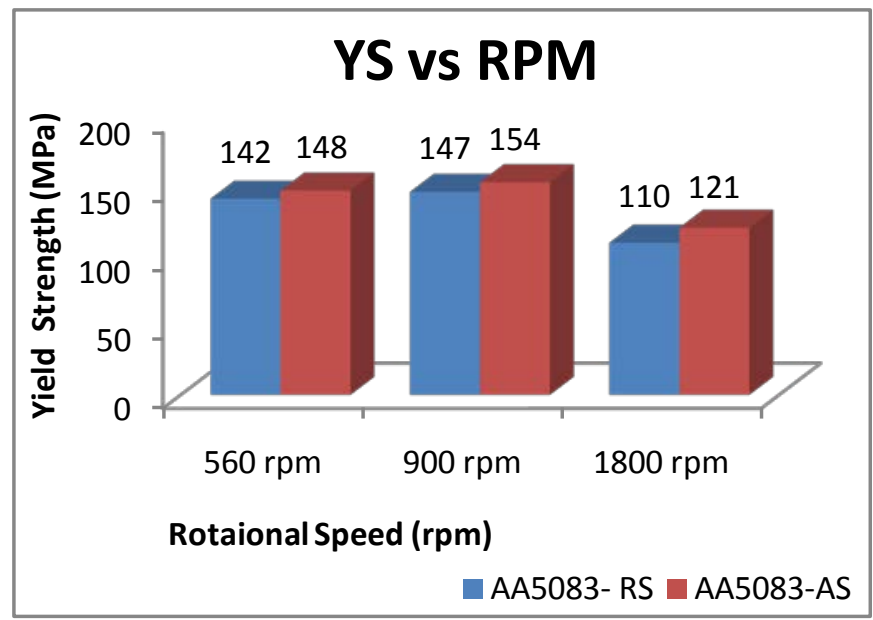

Figure 7: Effect of Tool Rotational Speed on Yield Strength

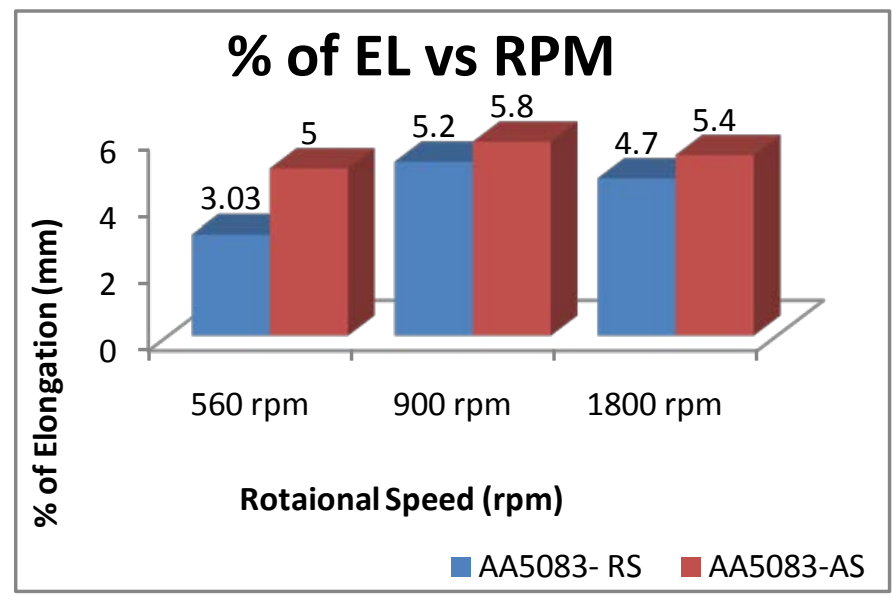

Figure 8: Effect of Tool Rotational Speed on \% of Elongation 


\section{B. Microstructure Studies}

The optical micrographs at weld nugget of FSW of all the joints are shown in Fig.9 (a-h). From the micro graphs it is understood that there is in appreciable variation in average grain diameter of weld region in AA5083 and AA6061alloy. Because of FSW, the coarse grains of parent metal are converted into fine grains in the weld nugget. The joints fabricated with a rotational speed of $900 \mathrm{rpm}$ with a constant welding speed of $40 \mathrm{~mm} / \mathrm{min}$ and $\mathrm{H} 13$ tool contain finer grains in the weld region compared to other joints. This is one purpose behind higher tensile properties of these joints contrasted with different joints. From the micrographs, it is surmised that there is an appreciable variation in grain size across the welds, this is a result of inadequate plastic flow and thermal exposure, It has been seen amid this work the aggregate effect energy increased in the friction stir welding of AA5083 and AA6061 alloy for both temper conditions especially at $900 \mathrm{rpm}$ and $40 \mathrm{~mm} / \mathrm{min}$ with respect to the base metal while rotation and transverse speed have little effect on the impact value of (high strength) results were very close to each other. Finally it is important to specify that the relation between rotation speed, weld speed and input heat which influence on the effect value seems to be compound what's more, rely on upon the material properties being welded, Grains are relatively smaller in the retreading side (RS) of SZ compared to the advancing side (AS), and this is caused by the greater straining in this location.

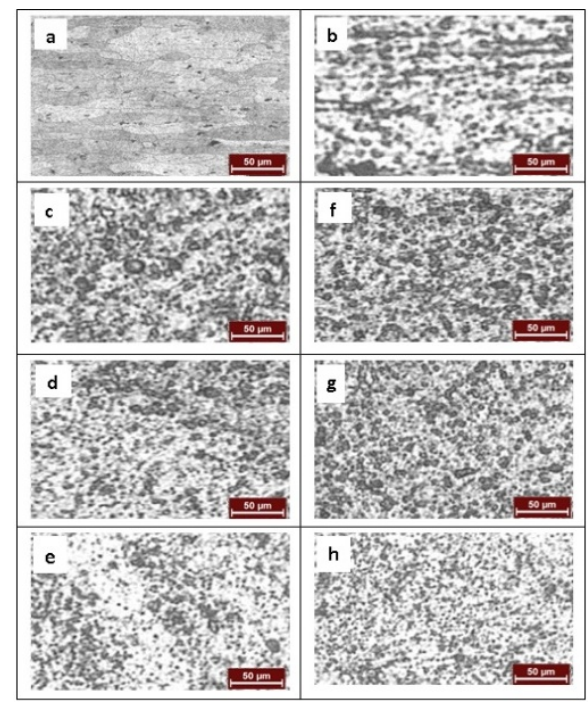

Figure 9: (a) Optical Microstructure as base Metal AA6061 (b) Base metal AA5083. Optical microstructures of SZ/weld nugget of the joints where AA5083 fixed at advancing side:(c) at $560 \mathrm{rpm}$ (d) at 900rpm (e) at 1800rpm. Optical microstructures of SZ of the joints where AA5083 fixed at retreating side: (f) at $560 \mathrm{rpm}$ (g) at $900 \mathrm{rpm}$ (h) at $1800 \mathrm{rpm}$

\section{Hardness}

The hardness was measured along the weld of the stir zone with Vickers microhardness testing machine, and the values are given in Table 4 . The hardness of base metal is 96HV (AA5083) and 120HV (AA6061). The joint fabricated with the rotational speed of $900 \mathrm{rpm}$, welding speed of 40 $\mathrm{mm} / \mathrm{min}$, recorded higher hardness $(84 \mathrm{HV})$ in the stir zone, and this is additionally one reason for superior tensile properties of these joints compared to other joints. These are two primary purposes behind the improved hardness of stir zone. Firstly, since the grain size of stir zone is much finer than that of parent metal, grain refinement has a critical impact in material strengthening, secondly the little particles of intermetallic compounds are additionally an advantage to hardness improvement. Higher tool rotational speed resulted in higher heat generation and this lead to the excessive release of stirred material to the upper surface which results in lower hardness. The microhardness values in all welding areas are reduced compared with that of base metals Figure 10 and 11 shows the Vickers hardness profile across the centerline of friction stir weldments for the case of using rotational speed (560, 900, and $1800 \mathrm{rpm}$ ) at constant traverse speed of 40 $\mathrm{mm} / \mathrm{mi}$. It's clearly observed that the maximum hardness across the centerline of all the weldments is found to be at the HAZ/TMAZ interface zone of the aluminum alloy 5083H321, while there is a significant hardness decrease at the HAZ/TMAZ interface zone of the aluminum alloy 6061-T6.

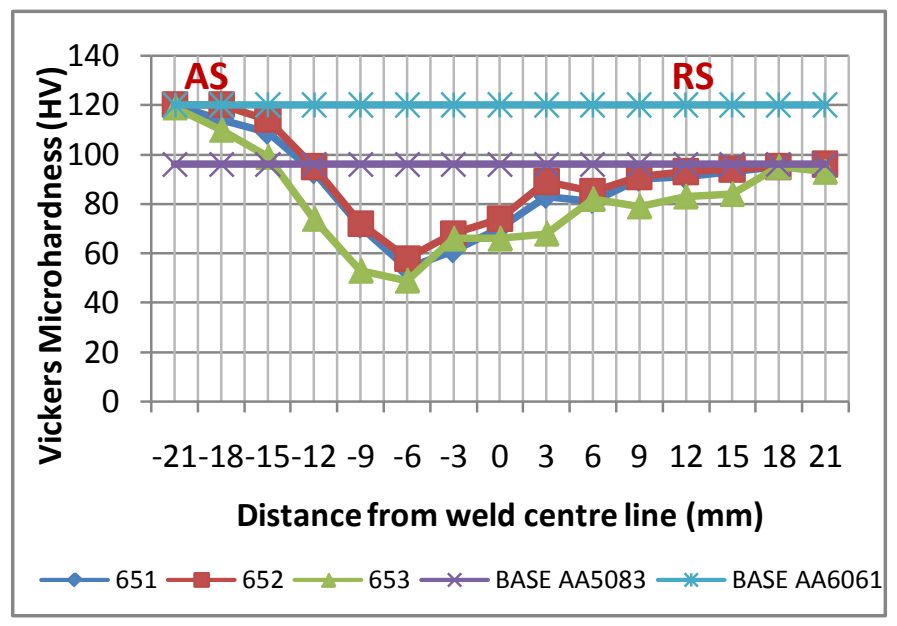

Figure 10: Vickers Hardness Profile Across the Centerline where AA5083 Fixed at Retreating Side (RS).

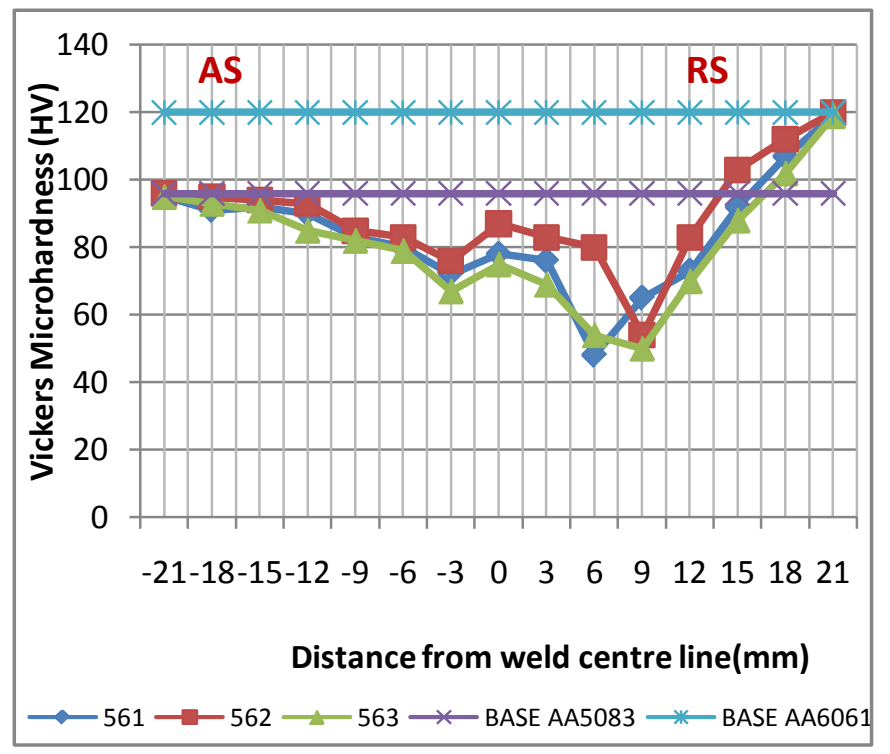

Figure 11: Vickers Hardness Profile across the Centerline where AA5083 Fixed at Advancing Side (AS) 


\section{Impact Toughness}

Charpy impact toughness of FSW joint was assessed and displayed in Table 4.The impact toughness of unwelded base metal is 16J (AA5083) and 8J (AA6061).However, the impact toughness of FSW joint with notch placed at the SZ region and reached maximum $29 \mathrm{~J}$ at $900 \mathrm{rpm}$, compared to the other rotational speeds when AA5083 located advancing side. This might be because of optimum heat generation which is adequate to bring about free flow of plasticized material

\section{CONCLUSION}

In this study, the effect of rotational speed on the microstructural changes and the mechanical properties of dissimilar friction stir welding of AA5083-H321 to AA6061T6 alloy have been investigated by using a vertical milling machine.

Following conclusions are made:

1. The weldments have no visible defects, weld surface is uniform with better surface appearance and have no pores and discontinuities for the inside part.

2. It was observed that rotational speed more affects grain refinement of material. The micro hardness of nugget zone is less compare to base metal.

3. The better condition of FSW for a $5 \mathrm{~mm}$ thick of dissimilar aluminum alloys 5083-H321 to 6061-T6, which produces $63 \%$ welding efficiency (196MPa), at $900 \mathrm{rpm}$ rotational speed and $40 \mathrm{~mm} / \mathrm{min}$ traverse speed are determined when the aluminum alloy 5083H321 is located on the advancing side.

4. At $900 \mathrm{rpm}$ mechanical properties are yield strength, ultimate tensile strength, \% of elongation, Vickers microhardness and impact energy are exhibited higher mechanical properties compared to those of other rotational speeds when the aluminum alloy 5083H321 is located on the advancing side.

5. With increasing rotational speed mechanical properties increases and reaches maximum then decreases.

\section{ACKNOWLEDGMENT}

The authors would like to thank the authorities of OU Hyderabad, DMRL Hyderabad and Vasavi College of Engineering, Hyderabad, TS, India for providing the facilities to carry out this work.

\section{REFERENCES}

[1] W. Thomas and P. Vilaca, "Friction stir welding technology" SpringerVerlag Berlin Heidelberg, Vol. 8, Pp. 85-124, 2011.

[2] G. Mathers, "The welding of aluminum and its alloy", Woodhead Publishing ltd, Pp.161-165, 2002.

[3] R.S. Mishra, "Friction stir welding and processing Journal of Center for Friction Stir Processing", Department of Materials Science and Engineering, University of Missouri, Rolla, 2005.

[4] Akinlabi and Esther Titilayo, "Characterization of dissimilar friction stir welds between 5754 aluminum alloy and C11000 Copper”, Nelson Mandela Metropolitan University, 2010.

[5] Terry Khaled, An outsider looks at friction stir welding, Report: ANM112N-05-06, Ph.D. Chief Scientific/Technical Advisor, Metallurgy Federal Aviation Administration 3960 Paramount Boulevard. Lakewood, Pp. 627-5267, 2005.
[6] R. Rai, A. De, H.K.D.H. Bhadeshia and T. DebRoy, "Review: friction stir welding tools", Science and Technology of welding and Joining, Vol. 16, No. 4, Pp. 325-342, 2011.

[7] C. J. Dawes, "Friction stir welding", The Welding Institute, Abington Hall, Cambridge adapted for TALAT by Roy Woodward, Birmingham and Christian Leroy, 1999.

[8] K. Nakata, Y.G. Kim, M. Ushio, T. Hashimoto and S. Jyogan, "Weldability of High Strength aluminum alloys by friction stir welding" ISIJ International, Vol. 40. Pp. S15-S19, 2000.

[9] Ying Li, "Flow visualization and residual microstructures associated with the friction-stir welding of 2024 aluminum to 6061 aluminum”, Materials Science and Engineering A271, Pp. 213-223, 1999.

[10] J.N. Pires, A. Loureiro and G. Bölmsjo, "Welding robots: technology, system issues and application”, Springer Science \& Business Media, 2006.

[11] Calvin Blignault et al. "Design, Development and Analysis of the Friction Stir Welding Process", Msc Thesis, electrical, industrial \& mechanical engineering Port Elizabeth Technikone, 2002.

[12] K. Kumar and S.V. Kailas, "The role of friction stir welding tool on material flow and weld formation”, Materials Science and Engineering: A, Vol. 485, No. 1, Pp. 367-374, 2008.

[13] Won-BaeLee. Et.al., "Mechanical Properties Related to MicrostructuralVariation of $6061 \mathrm{Al}$ Alloy Joints by Friction Stir Welding”, Materials Transactions, Vol. 45, No. 5, 2004.

[14] M.A. Abdelrahman, M.M. Ghoneim, M.E. Abdelazim, M.M.R. ElKouss and N.A. Abdelraheem, "The effect of FSW tool geometry on AA6061-T6 weldments", Arab Journal of Nuclear Sciences and Applications, Vol. 45, No. 2, Pp. 407-418, 2012.

[15] P. Cavaliere, "Effect of welding parameters on mechanical and microstructural properties of dissimilar AA6082-AA2024 joints produced by friction stir welding”, Materials and Design, Vol. 30, Pp. 609-616, 2008.

[16] Aluminum to 6061 aluminum, Department of Metallurgical and Materials Engineering, Materials Science and Engineering A271, Pp. 213-223, 1999.

[17] I. Shigematsu, Y.J. Kwon, K. Suzuki, T. Imai and N. Saito, “Joining of 5083 and 6061 aluminum alloys by friction stir welding”, Journal of Materials Science Letters, Vol. 22, No. 5, Pp. 353-356, 2003.

[18] Morteza Ghaffarpour, Sinakolahgar, Bijanmollaei Dariani and Kamran Dehghani, "Evaluation of dissimilar welds of 5083-h12 and 6061-t6 produced by friction stir welding”, The Minerals, Metals \& Materials Society and ASM International, 2013. 